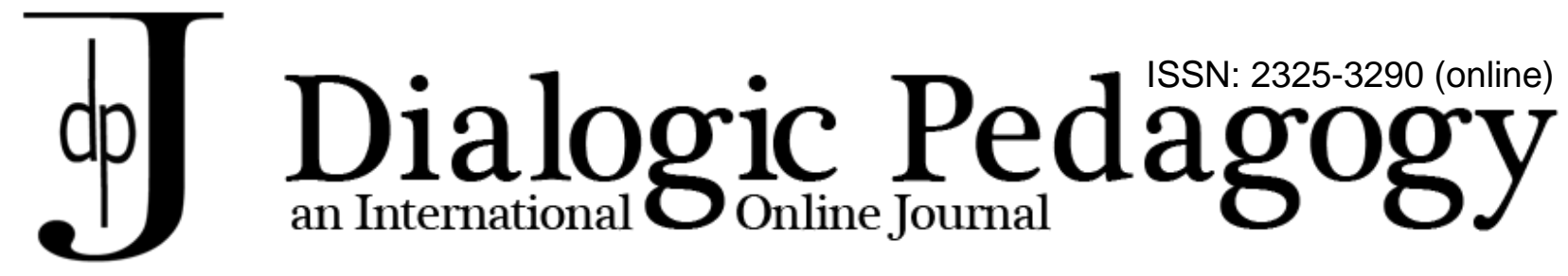

\title{
Disengagement, Pedagogical Eros and (the undoing of?) Dialogic pedagogy
}

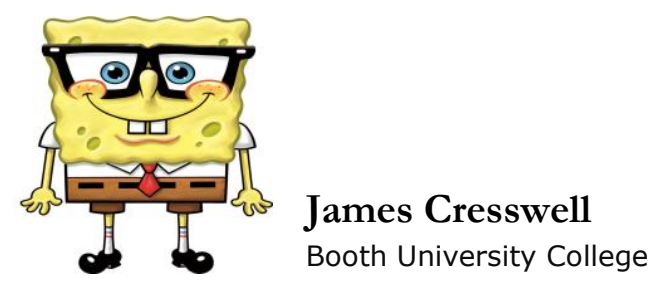

\begin{abstract}
Dialogic pedagogy is an approach to education influenced by Bakhtin, Freire, and others. It is an approach that is critical of conventional education, which tends to be didactic and alienating to students. Student engagement is made central as dialogue takes priority over standardization and core cannons of content. Dialogic pedagogy also emphasizes the importance of communities of learners where teachers are co-learners along with students as all parties work on problems together. I seek to raise challenges to Dialogic Pedagogy and these come from scholars working on the "conduct of everyday life" and from Charles Taylor's notion of "strong evaluations". The conduct of everyday life involves a focus on first-person subjectivities with an eye to their constitution in social and power relations. Strong evaluations enhance this discussion by addressing how people can engage in decisions that involve weighing options about the qualitative kind of person one is. I outline how education involves a conduct of everyday life where strong evaluations are promoted. Taking such an approach to education grounds two challenges to dialogic pedagogy. One challenge is that students are reticent to engage in strong evaluations and the modern identity is one disposed to disengagement. The converse challenge is that student engagement entails pedagogical eros, which is easily converted into power and abuse by a pedagogue.
\end{abstract}

James (Jim) Cresswell is an Associate Professor in Psychology and Behavioural Sciences at Booth University College, Canada. His work has been supported by organizations such as the Social Science \& Humanities Research Counsel, Templeton Foundation, and Murdoch Charitable Trust. His work is largely influenced by the philosophy of Mikhail Bakhtin and cultural psychology. Of special interest is Bakhtin's work on aesthetics in relation to language and how it can enhance current work in education, philosophy of mind, cognitive science of religion, and immigration.

$\cos 0380$

\section{Introduction}

Before coming to be involved in DPJ, I studied critical/cultural psychology with a focus on the work of Mikhail Bakhtin (e.g. Cresswell, 2011). This work addressed the dialogicality of personhood, but being an academic working at teaching-focused universities has made education an important topic of study for me. In this editorial, I draw on my background and my comparatively recent experience with DPJ to speculate about two challenges facing dialogical pedagogy. The objective of this editorial is to outline how disengagement and pedagogical eros are two issues that we need to think about engaging in 
dialogic pedagogy. I seek to set the ground to raise issues that we ought to be talking about. Doing so requires that I first outline the background perspective that grounds the challenges I present. This background involves a discussion of scholarship on the conduct of everyday life (see Dreier, 2016) and Charles Taylor's $(1989,1999)$ notion of strong evaluations. It will then be followed by a brief synopsis of dialogic pedagogy and to so show resonance among the forgoing. Doing so sets the stage for my challenge to dialogic pedagogy.

\section{Critical/Cultural Psychology \& the Classroom}

\section{Conduct of Everyday Life}

The "conduct of everyday life" is a phrase originating from an interdisciplinary group of researchers. Although this approach emerges in psychology from the work of Holzkamp (2013) and is promoted largely by a psychologist named Ole Dreier (2016), its interdisciplinary roots speak to a wide range of disciplines including education. Dreier argues that the conduct of everyday life involves the exploration of human subjectivity. This approach is one that points out how researchers can lose sight of everyday subjectivity in the development of theory and so presupposed theory or specified research interests in the industry of academy can set researchers' interests above that of those they study. Scholars working on the conduct of everyday life avoid any distinction between talking about a theory dealing with the conduct of everyday life and the conduct of everyday life itself. While such scholars are not against theorizing per se, the do critique theorizing from a third person perspective. No person can escape the conduct of everyday life and theorize about others without personal involvement. It involves examining what it is like to live life from the perspective of one living it.

Examining the first person perspective is important but it does not follow that the conduct of everyday life is not just about individual subjectivities. Dreier (2016) points out that the first person perspective is one of a situated subject. Subjectivities are constitutionally situated in sociocultural contexts and so, at a very basic level, this situatedness pertains to interpersonal relationships. Højholt \& Schraube (2016), for example, argue that it is important to take into account how people produce and reproduce their lives collaboratively through interpersonal activities embedded in sociocultural, economic, and political contains. It is through constrained activities like talking, playing, working, and so on that people engage with others and build their subjectivities. Subjectivities are co-created together with others and so examining them includes examining the interpersonal practices by which people conduct everyday life.

Considering the first person perspective also includes the loci of the reification of social structuring because interpersonal interactions are where such structure is constituted. Dreier (2016) reviews the conduct of everyday life to address how social and interpersonal practices are intimately entwined with what we often consider to be wider social structures. Social structures are held in place through appropriated ideology and practices that reify the machinations of power. Persons who participate in social practices participate in such structures that entail differences in power and control. Looking at such social practices allows us to grasp how people live in first person subjectivities that are not merely individualistic or independent. It includes examining the establishment of joint arrangements that enable such social structure to be continually reified. They become routines that structure and reify more extensive social arrangements and so it is important to examine the first person perspective for this reason. Considering the conduct of everyday life highlights the social structure of practice in everyday life and therein sheds light on structure of society as it manifests in the arrangements of everyday life. 
One of the strengths of work in the conduct of everyday life is the acknowledgment that the notion of the situation - singular, objective, and unambivalent - is naive. Dreier (2016) argues that the singular notion of situation is an abstraction that is convenient for academics but it can't be studied in singular terms if we can look at the conduct of everyday life. A given context may involve multiple situations insofar as there can be competing realities and worlds at stake at one point in time. Interests and perspectives are not just differences in something simple like shallow opinions insofar as they gesture towards societal tensions and social problems (Højholt \& Schraube, 2016). Dreier (2016) therein argues that such differences in the concrete practices of everyday life entail intra-subjective discourse enmeshed with everyday concerns. They can also be clues to how one can look to change by considering how human beings take part in reproducing and changing society. As such, the conduct of everyday life involves considering how people navigate among complex realities to exercise agency (see also Højholt \& Schraube, 2016).

A result is that the conduct of everyday life involves looking at how people manage such complexities simultaneously as well as diachronically. It is here that we see the importance of the notion of conducting insofar as moving through spheres of life includes developing practices in many forms of life (Dreier, 2016). Such forms are infused with their own power structures and ideological agendas, which means that life is replete with discontinuities that people have to deal with. The conduct of everyday life involves bridging across spheres of life as people attempt to coordinate life with others. Sometimes such attempts are successful and sometimes they are not because attempts at such bridging can be more or less successful as some ideologies are rejected as others are recapitulated. Such dynamic tensions are part of conducting life in a way that one is able to get along with others well enough, one hopes! Of course, this not always possible and ruptures happen.

What is interesting about the conduct of everyday life is that people often navigate complexities in ways that show creativity - satisfying contradictory ideologies in unique ways so that people are not socially programmed automatons. There is thereby a kind of agency that we see in the conduct of everyday life insofar as people are able to transcend a given situational set of demands and act in unique ways. People establish routines to accomplish living in ways that are subject to decisions and choice via such transcendence. The different inequalities and tensions are managed in the course of accomplishing a modus operandi that fits with one's interlocutors. The advantage of the conduct of everyday life is that it links spheres of activity and allows us to talk about how people individually coordinate pursuits from one place to another among and with different people.

Work on the conduct of everyday life is good because it focusses our attention on how education involves the conduct of everyday life. It shows us how first person subjectivities matter and yet does not diminish an important discussion of power, authority, and agentic resitance. In so doing, the conduct of everyday life entails learning as situated in multiple zones of conflict where people are agents that uniquely shape their lives. Below, I will further elaborate on this work in light of education, but I first want to turn to Charles Taylor $(1989,1999)$ because his ideas add to this work by offering further insight through his notion of strong evaluations.

\section{Strong Evaluations}

Taylor's (1989) Sources of the Self traces the sociohistorical development of self. He has attempted to discuss human experience in general and I have found his work to be, at times, ethnocentric. His arguments fit well with a western intellectual tradition but it remains unclear how well it works elsewhere. Like most intellectuals who take on large topics like the development of the modern self, he opens himself to the critique of exception, which is when one can always think of some people 
group or exemption to his claims. This challenge notwithstanding, his work has been highly influential and generative because he does articulate important themes. He opens up important themes worth discussing as he carefully brings together a wide range of social and philosophical trends. Rather than dismissing Taylor immediately, I argue that he provides a voice that can enhance our dialogue about dialogic pedagogy.

Taylor (1989) opens with a discussion about how being a self is inseparable from existing in a space of moral issues. This discussion is about how humans can be deeply moral and compelled by things that matter deeply to them. Human life can be about engaging with an experience of struggling with what is right or good and this discussion is grounded in what he calls "strong evaluations". Sources does not really spell out with a lot of clarity what this phrase means, but it is carefully articulated ten years later. Taylor (1999), therein, draws on a well-worn philosophical distinction between first and second order desires. A first-order desire is to want something like a desire to simply feel pleasure from an outcome, choosing between sweat treats for example. We want our selves, however, to be dispositionally inclined to things that would be deemed as good and admirable and this wanting is a second-order desire. He points out that what is distinctively human is the capacity to evaluate our desires insofar as we can see some desires as good and others as bad. We can desire that we have certain first-order desires over others and this is what amounts to a second-order desire. That is, a second-order desire is to have a desire whose object is to have a certain desire (first-order desire). People can want themselves to be inclined towards things that they evaluate as good and admirable - whatever that means within a particular framework.

Taylor's (1999) discussion of first and second order desires sets a background for explaining what is meant by strong and weak evaluations. Weak evaluations are concerned with basic outcomes where an option is considered good if it satisfies a first-order desire. A weak evaluation means that something is desired and an option is good to take if the desire is satisfied. Choosing one option over another simply enables us to have our desires met and so options often preclude each other. Taylor calls these weak evaluations because an option is good so long as a desire is met and so the depth and quality of deliberation are not terribly relevant. Strong evaluations are concerned with quality of motivation in a sense that resonates more with second-order desires. Instead of assessing options on the base of whether a first-order desire is satiated, it is about assessing the qualitative worth of different desires as they relate to outcomes. An outcome is considered good on a much more complicated basis because we can include our considerations of whether the desires entwined with the outcomes are desires that we want to dispositionally embody. The notion of good is therein accompanied by some other evaluative terms and considerations. The action one chooses may or may not preclude other options as it may not necessarily involve incompatible decisions. To evaluate strongly involves wanting to be a certain kind of person or living a certain kind of life. We characterize such 'certainties' in a complex interconnected web of meanings and desires. This is the moral space in which Taylor (1989) earlier describes as essential to humans. It involves largely implicit qualitative distinctions of worth that are entwined with our decisions about what one ought to do and what one ought to be. The fact that such deliberations are more ridden with conflict and they are not contingent on merely satisfying a desire, Taylor calls them strong evaluations.

Taylor $(1989,1999)$ is clear that evaluations are integrally entwined with our participation in communities. Much like Dreier (2016) argues that subjectivity is constituted in sociality, Taylor (1999) argues for a communitarian approach. The latter turns to a discussion on language to explain how the experiences that are entwined with strong evaluation are socioculturally constituted. Language is not owned by any particular person and is used in a way recognizable by a community. It is a normative 


\section{Disengagement, Pedagogical Eros and (the undoing of?) Dialogic pedagogy}

James (Jim) Cresswell

phenomenon. Taylor notes that language does not just label experience because we cannot just change the label of an experience at a whim. Language is constitutive of experience and we draw on language to articulate our experience, leaving us with a sense of when we have got the articulation correct and when we have not. Language provides a symbolic medium by which higher and lower goals can be articulated and constituted. Without a communally shaped language there would be no way to articulate the kinds of choices that are at stake in life. In fact, the language that we learn to speak along with others is a constitutive force that shapes what counts as good or right. First order desires are not, thereby, merely something like biological drives. A characterization of such basic desire betrays the complexity of human experience. They are more like seemingly on-hand inclinations and so desire, in the case of strong and weak evaluations, is not about a simple dichotomy between biology and cultural sophistication. It is on such grounds that Taylor (1989) argues that doing without such linguistically constituted frameworks is impossible for us. He argues that stepping outside of frameworks is stepping outside of what is essential to us.

Taylor (1999) is well aware of how multicultural pluralism means that desires differ markedly from culture to culture and community to community (1999, see also 1994). He writes that "... frameworks today are problematic. This vague term points towards a relatively open disjunction of attitudes. What is common to them all is the sense that no framework is shared by everyone, can be taken for granted as the framework tout court, can sink to the phenomenological status as unquestionable fact" (1989, p. 17). Different communities would have different frameworks and so multicultural pluralism means that it is unlikely that there is a framework shared by everyone. People are often presented with goods that challenge and displace others. Weak evaluations are easier when there is not such pluralistic challenge to what feels 'natural'. In contrast, strong evaluations involve evaluative contrasts ranging over desires grounded in different communities of practice. It becomes hard to sustain a consistent moral ontology because such contrasts lead to uncertainties on our own beliefs. Such conditions lead to a reflexive stance which is quite radical in the sense that the kinds of tensions addressed in the conduct of everyday life have serious existential weight. As such, strong evaluations are not merely " $A$ " being more desirable than "B" on the basis of one framework. Such conduct of everyday life is about articulating and deciding among such frameworks. Thus, a strong evaluation is a condition of articulacy that involves a deeper sense of the world because it characterizes motivation at a greater depth. Strong evaluations are about the deeply experienced tensions that come from learning language and, as noted above, the contrast of subjectivities entwined with participation in multiple communities.

Just like researchers interested in the conduct of everyday life have an interest in agency, Taylor (1989, 1999) shows a similar interest. Pluralism and second-order desires or evaluating desires is essential to human agency. One is potentially in a place where there are multiple available options that are part and parcel with the multiple zones of conflict spelled out in the conduct of everyday life. Here is where strong evaluations begin in the sense that there can be competing moral ontologies as there are different lifeworlds juxtaposed. There is not a view from nowhere that is taken when making decisions but rather something like an intrapsychic dynamic of competing subjectivities. Such experience is entwined with strong evaluations and is necessary to our notion of the human subject conducting everyday life. Taylor argues that an agent who cannot evaluate desires lacks the reflective capacity which we associate with the human agent. Not exercising such evaluations means to have no depth essential to humanity.

An agent is thereby responsible for what he does and for the evaluations that he makes in two senses. In one sense, one is responsible to others in one's life. Second-order desires are not just seemingly given like first-order desires because second order desires entail more existentially challenging acts of responsibility, relative to weak evaluations. This sense means that the choices people enact have 
consequences for how we get along with others and the continued fit people have (or don't have) with our families political, economic, and/or religious communities. Taylor (1991) draws on the Bakhtinian notion of answerability to show that our lives are constantly responding to others as we answer to them. This quality of the conduct of everyday life is what Dreier (2016) and others are getting at with the discussion of how we negotiate the conduct of our everyday life in the midst of tensions.

In another sense, one is responsible to be a strong evaluator and Taylor (1999) argues that strong and weak evaluations introduce different kinds of selves. One can reduce deliberation to weak evaluation and such would involve conducting everyday life as a subject who is a simple weigher. It is possible to make decision based on caprice and shallowly inconsiderate of the bigger questions and meanings involved in options. It can involve simple decisions where one dismisses obligations to diverse communities as one goes with whatever feels simply right. In a tragically ironic kind of manner, Taylor argues that this sort of decision making is a hallmark or neoliberal individualism:

\footnotetext{
Of course the independence can become a very shallow affair, in which masses of people each try to express their individuality in stereotyped fashion. It is a critique that has often been made of modern consumer society that it tends to breed a herd of conformist individuals. This is indeed a mockery of the pretention of the culture. But just for that reason we can't conclude that the existence of a traditional culture of independence itself empties individuality of its meaning. (1989, p. 40).
}

In being a simple weigher who does not engage in strong evaluations, one can become shallow and conform to whatever consumer culture prompts, which therein strips one of authentic agency. One does not find creative solutions to transcend community and be unique (see Cresswell, 2011), which means people can be relegated to being part of 'the herd'. There is still a deeper meaning entailed in weak evaluations but it is obfuscated in the denial of responsibility to conduct everyday life on the basis of strong evaluations. What is articulated in Sources is that we run the danger of falling into weak evaluations as a mode of living in contrast to the possibility of engaging life at the level of strong evaluations. The conduct of life can be differentiated as strong or weak and this is how our understanding of the conduct of everyday life is enriched by Taylor.

\section{Implications for Education}

The forgoing has clear relevance to the topic of education, as described by Schraube \& Marvakis (2016). They point out how the conduct of everyday life entails understanding learning as participation in social practices. To understand this conceptualization of learning it is helpful to articulate the perspective against whom they position themselves, which is what they call the "transfer model of learning". The transfer model represents learning as the transfer of information from the teacher to the learner. A problem that they identify with this model is that learning is treated like a direct result of teaching. Readers of DPJ will be familiar with how understanding and learning is more than a direct result of information transmitted from a teacher (see below). Fixed procedures for teaching are insufficient because learning is not a one-way process. Teachers and students form a reciprocal relationship where qualities and the conduct of everyday life in students bears on the process.

In contrast to the transfer model, Schraube \& Marvakis (2016) explain that the conduct of everyday life involves an active relational contextual approach to learning. It involves subjectivities constituted in shared practices and interpersonal interactions as described above. Learning is a developing ability to practice subjectivities that one theretofore did not know. Schraube \& Marvakis (2016) thereby argue that one cannot reduce learning to a knowledge of content required to pass a test. 
Demonstrating learning involves a stylistic appropriation of social practices that amounts to social labor. Situated learning anchors activities of learning in the world and so demonstrations of learning are about explaining world in and through participation in social practices. It is about participating in action possibilities that are contextually entwined with social meanings of the students and instructors instead of merely passive reception of content.

Because the conduct of everyday life involves a reciprocal relationship among students and instructors, Schraube \& Marvakis (2016) argue that education is not neutral or free of conflict. The collision of social practices and different subjectivities in education means that it is a place of contested meanings. The conflictual character of education opens up possibilities for learnings wherein the conduct of everyday life and be shaped and reshaped. Conflict is taken seriously and acknowledged in contrast to the transfer model wherein it is denied through the masking power of a pedagogue. Students and teachers can take this "defensive mode" of learning that overtly curtails development and change in the conduct of everyday life. It reifies a separation of learning from everyday activities predicated on presupposed separation in society that does not work in the conduct of everyday life where people actually integrate diachronically and synchronically. In contrast, learning can involve moving forward and reshaping how one deals with everyday problems and subject matter. This conduct of learning is what Schraube \& Marvakis refer to as expansive learning. Students and teachers can be "affinitive" where they work on problems and seem to come to solutions. This solution is temporary, however, as it is possible to be redefined and open up problems for new forms of synthesis and new possibilities. It is in this way that education is a cooperative endeavor in the conduct of everyday life. It leaves us with a model of education that is not just transference of information, but it is a conduct of everyday life. In short, it gives us a good sense of education in terms of what is happening on the ground.

Considering the conduct of everyday life involves learning situated in multiple zones of conflict where agents uniquely shape their lives and Taylor shows us how this includes the potential for strong evaluations. The first person subjectivities of students matter and not all subjectivities are the same. Some can be reminiscent of weak evaluations where subjectivities involve decisions as if they are first order desires. While not succumbing to the transfer model of education, this sort of education could be masked as "student engagement" where it tunes into student interests and first order desires. Much like the learner-centered trade literature that is often about seducing students into learning by cleaver tricks to appeal to their interests, education can be about appealing to first-order desires. "Getting students interest and keeping it" (Bain, 2004) can look like engagement because it appeals for first-order desires. Taylor inspires awareness of how weak evaluations can be promoted with the result of herds that seemingly do their own thing while in fact conforming to whatever neoliberal consumerism marketing genius designs.

Education can, alternatively, offer a conduct of everyday life entailing subjectivities of strong evaluations. This model of student engagement involves retaining student experience and not negating it as the transfer model entails. It does not fetishize personal experience by playing to first-order desires insofar as real competing moral ontologies are brought into a zone of conflict. Engagement involves agency in the sense of strong evaluations where instructors challenge students as the former are themselves challenged. Risking frameworks is part of the conduct of everyday life in education and it is for the instructor as well as the students. Judgment and critique are part of education and not just validation of one's experience for its own sake.

The conduct of everyday educational life includes strong evaluations and the realities of power and authority. Just like the conduct of everyday life involves power and authority and the negotiation 
thereof, including strong evaluations entails such negotiations. It is important to bear in mind that strong evaluations involve constant weighing and testing of options. They are not compatible with monologic tendencies where one authoritative discourse tends towards prevailing at the expense of all others. This resonates with the well-worn challenges that we see in the likes of Freire's (2002) challenging authority in dialogical education and Postman's (1971) admonition to embody teaching as a subversive activity. Strong evaluations mean knowing risk and what happens when power and authority are violated. It can involve choosing to face the wrath or not, but it is a choice made as a strong evaluation and so engages communities and deals with ideology.

\section{Dialogic Pedagogy}

Dialogic pedagogy partly has its roots in the Freire's (2000) Pedagogy of the Oppressed and related approaches that critique conventional educational practices (e.g. Shor, 1987; Shor \& Freire, 1987). Matusov's (2009) Journey into Dialogic Pedagogy stays faithful to this critique through a careful discussion of Socratic dialogues. Matusov notes how Socrates often starts with "pedagogical diagnostics" where he unearths what someone thinks in order to correct them. Such a pedagogical style has found its way into current educational praxis where fostering conversation tends to morph into testing curriculum and prescribed cannons of information (see Hayes \& Matusov, 2005). It involves testing for knowledge about information divorced from everyday experience. The Bakhtinian roots of dialogic pedagogy highlight how the conventional approach amounts to a chronotope where knowledge and skills are treated as immutable across people and across practices and situations (see Matusov, 2015b).

The results of conventional schooling can be quite negative as Matusov (2009) writes:

\footnotetext{
I argue that monologic pedagogy; prevalent in many conventional classrooms, is responsible for at least three major mutually related problems: alienation of students from formal education, irrelevancy of the school curricula for societal and personal development, crisis of teacher authority. (p. 145).
}

As a teacher creates an illusion of certainty where all other answers are bad, students learn to suppress what they really think in order to cooperate with a teacher's agenda. The alienation of students is seen in how presenting correct answers does not mean that students will accept them. Shor (1987) pointed out that students learn to "sit tight" and "learn the score" in terms of how to play the education game, which also entraps teachers as well. Students can be disciplined into remaining with an educational curriculum in a way that defines their experience as irrelevant (see Matusov \& Miyazaki, 2014). A result is that a conventional school chronotope is one that values unconditional cooperation (see also Matusov, 2015a). The issue of teacher authority is one of eliciting cooperation and so the ontological authority of teachers pertains only to the classroom game.

Dialogic pedagogy attempts to offer an alternative approach to conventional schooling. Hayes and Matusov (2005) note how dialogue does not diagnose students to reveal errors or lend itself to be used as a technique to make students friends in a way that seduces them to presupposed truths (see Shor \& Freire, 1987). One of the key points that emerges is that authentic dialogical relations in the classroom is the non-transparency of student consciousnesses (see Matusov \& Miyazaki, 2014). Students cannot be known a priori by the teacher and so conditions must be set to enable the former's experiences to manifest in a mode other than the detection of error. Such conditions mean that students' positions are accepted as legitimate and teachers may not know the meaning of students' work without dialogue and orientation. For example, Elkadar (2015) discusses the issue of multicultural education and how students' voices can be suppressed. The politicizing of multicultural education effectively makes it 


\section{Disengagement, Pedagogical Eros and (the undoing of?) Dialogic pedagogy}

James (Jim) Cresswell

monologic and suppresses student agency. In contrast, Elkadar argues that dialogic education promotes student agency by welcoming resistance. Student agency emerges when teachers respect all voices (not just politically correct ones) because dialogue then becomes possible. Dialogic pedagogy therein involves an attempt to promote students' responsive action in class and this is very different from mere cooperativeness. In short, dialogic pedagogy follows inspiration from Shor (1987) that teachers interrupt ordinary expectations of what class structure should be in order to create an authentic dialogue.

One of the chief ways that such interruptions occur is through a suspension of defined educational ends/standardization and a turn to problem-based learning. Matusov (2009) notes that prescribed end points contradict open-ended spirit of dialogue needed for authentic student engagement insofar as dialogue demands its own emergent endpoints (see also Matusov \& Miyazaki, 2014). Similarly, Nissen (2015) notes how a focus on standardization degrades the relevance of everyday human complexities. He argues that authentic dialogue involves sense-making practices that occupy interlocutors. Such sense-making in a milieu of an ill-defined problem lends to a communal constitution of ideas: a collectivity that establishes its own knowledge and gives students a voice. Where mass higher education has become largest warehouse for the institutional educational end-game to be played (see chapter one of Shor, 1987), suspending definitive standards leads to place where students can be personally engaged.

Matusov (2009) argues that what goes hand-in-hand with the suspension of standardized ends is a problem-based learning. For example, Arya and Parker (2015) address climate change discussions among youth in order to demonstrate problem-based learning. The students learned how to evaluate evidence through engaging with each other on the problem of how to address climate change. The efforts of the teacher were not directed at teaching principles about climate change because they were focused on fostering student dialogue about a problem. The turn to problem-based learning is a continuance of ideas seen in Freire and Shor, who argue that teachers need to choose problems that come from students' cultures (see especially Shor \& Freire, 1987). This turn is a response to the growing monologicity emerging from the way that mass education has brought low culture of everyday life into contact with the traditionally high culture of "genteel" academe (see Shor, 1987). Dialogic pedagogy entails the notion that low culture is as valuable as any other form of life when it comes to learning. What matters is raising problems drawn from everyday life because a teacher cannot assume that all participants are automatically or non-problematically interested in a problem formulated in traditional education. Just as life involves solving problems, education can be about solving living problems. Instead of predefined ends, problem solving in the classroom becomes like everyday life where goals and the problem itself can be redefined (see Matusov, 2015a\&b).

Suspension of defined educational ends/standardization and a turn to problem-based learning set the conditions for what is called "ontological dialogue" in dialogic pedagogy. Drawing on the Bakhtinian distinction between authoritative and internally persuasive discourse, Matusov (2009) points out that conventional authoritative pedagogy is about knowledge removed from life. Such authoritative dialogue amounts to an epistemological form focused on a cannon of information. In contrast, internally persuasive discourse relates to an experience where one's being is engaged as one is personally drawn into the dialogue. Dialogue is thereby ontological and such learning cannot be separated from people because it is part of what defines them (see also Matusov \& Miyazaki, 2014). Where epistemological dialogue does not involve ontological meaning for participants, ontological dialogue involves a personal urgency because one is dealing with issues that are deeply entwined with selfhood. The problem of student disengagement becomes potentially minimized due to the fact that people's beings are brought to bear instead of being discounted. 


\section{Disengagement, Pedagogical Eros and (the undoing of?) Dialogic pedagogy}

James (Jim) Cresswell

Of course, ontological dialogue results in a very different kind of classroom space that is marked by what Matusov (2009) calls a "community of learners". A community of learners is not necessarily marked by studying a core domain of knowledge because it is marked by a community that takes dialogue seriously by virtue of seeing how it is ontological. Such a community involves honest dialogue where there is an ongoing testing of ideas and values against each other:

In my view, genuine education is not about placing the students into a situation in which the student would accept as true voluntarily by him/herself but it is rather about helping the student consider as many alternative options as possible from many diverse angles (i.e. internally persuasive discourse). (p. 36).

Where conventional knowledge is established through communal authority, understanding in dialogic pedagogy is established through testing in a milieu of ontological dialogue. Consider how Matusov writes:

In contrast, dialogic pedagogy is about colliding and testing diverse ideas presented by different voices, by different members of a community. It involves genuine interest in each other. In dialogical pedagogy, one does not look for student errors but rather learns from the student how the student sees the world and him/herself. Disagreements between the student and the teacher are valued, respected, and expected. (2004, p. 7).

Such practice stands in contrast to a context where the community about is not winning a debate or demonstrating one has knowledge aligning with authority. Consider, for example, Kamberelis et al. (2105) and their discussion of a classroom engagement with literature. Instead of the teacher having a pre-designed agenda for a class discussion, the teacher made space for the class to enter a free discussion. The teacher modeled questioning and then turned the discussion over to students so that the teacher's control was breached. It illustrates how texts are collaboratively produced over time in "mangles of practice". As such, ontological dialogue involves a community that is continually involved in "problem space" (see Matusov \& Miyazaki, 2014). A community of learners therein involves a community of constant dialogue where questions such as the following are continually asked: Do relevant people pay attention? Am I or others taken seriously? Do I or others provide support to each other in the act of learning? Is there respect in disagreement? Is there unconditional trust? (see Matusov, 2009).

Ontological dialogues in such communities means that subjectivities are also at stake insofar as a goal of dialogic pedagogy is the transforming of subjectivities within a community of learners. Matusov (2009) looks to Socratic teaching to show how education can involve internally persuasive dialogues that transform students' subjectivities. In one way, the change to student subjectivities means realigning themselves to a community of learners this quality of dialogic pedagogy was noted by Shor. Consider how Shor writes that "I must recognize that students cannot understand their own rights because they are so ideologized into rejecting their own freedom, their own critical development, thanks for traditional curriculum" (Shor \& Freire, 1987, p. 21). Good liberal arts education that is dialogical in nature "desocializes" people such that it is possible to break students and teachers from the conventional school model into which they have been socialized. Shor is interested in showing how class can become a place where people are de-socialized and re-socialized into a different dialogical milieu:

\footnotetext{
The teacher is the architect of this un-doing and re-doing. The extraordinary re-experience of the ordinary cannot begin or proceed without the teacher's counterstructures. This is an inspiring and awesome situation for teachers, who so often feel trapped in the slough of despond. So much can be gained or lost in the project of liberatory teaching. (Shor, 1987, p. 97).
}

Dialogic Pedagogy: An International Online Journal | http://dpj.pitt.edu DOI: 10.5195/dpj.2016.182 | Vol. 4 (2016) 
In this way, the classroom can become a space where there is push back against the boundaries of class consciousness because students are "expelled" from the regular mode of conventional school to re-enter it with a critical consciousness. Lemberger (2015) expands on this idea by discussing the nature of dialogue. The formulation of self is not a mental process, but rather one that happens interpersonally. Interaction is central to any human activity and this centrality includes the constitution of subjectivities. As such, dialogical grammar is a deep engagement with others that results in changes to one's subjectivity. Dialogue entails changes to student subjectivities that emerge in unpredictable ways contra to standardized learning objective like 'develop critical thinking'.

Students' subjectivities are also transformed through self-reflection in dialogic pedagogy. This change is entwined with the way that ontological dialogue involves contestation and debate about the means by which people frame their world (see Hayes \& Matusov, 2005). Matusov (2009) continues and expands on Shor's (1987) claim that dialogicality can lead to an extraordinary experience of life when it is seen from a new critical stance. The former writes about Socrates' "torpedo touch" wherein the world one takes for granted can be blown open through dialogue. Ontological dialogue involves a space where relationships and one's taken-for-granted reality can be redefined (see also Matusov \& Miyazaki, 2014). Hence, a community of learners involves a community that practices critical self-examination that can lead to self-generated critical student subjectivities (see also Matusov, 2015b).

Another key quality of dialogic pedagogy latent in the forgoing is the reconceptualizing of the role of the teacher (see Matusov \& Miyazaki, 2014). Shor (1987) identifies how the role of a teacher is not to primarily impart information because the role is more about promoting critical reflection in dialogue, as opposed to implementing standardized ends at the behest of bureaucratic managerial systems. Teachers must be sensitive to learners and listen carefully in such a way that they can be dynamically responsive to what they hear. A teacher may have experience and knowledge from which an exploration can begin and so a teacher does not naively deny what one thinks she or he knows. What demarcates a radical break from conventional schooling is that a teacher holds to a conviction that she or he can learn from students. Teacher subjectivities can also change as they are open to reconstruction. Ensuring dialogue means that there ought to be challenges to a teacher's knowledge and such challenges demystify the teacher's power, which requires a teacher to demonstrate competency in the course of dialogue (see Shor \& Freire, 1987). A similar theme shows up in contemporary scholarship in dialogic pedagogy where Matusov (2009), for example, turns a critical eye to the Socratic dialogues. The chief problem with Socrates is that he is never perplexed. Socrates asks leading questions that amount to faux questions where the answers are already known by him. His style of questioning continues into contemporary education where teachers engage in a triadic discursive sequence of question, student-response, and then teachercorrection (see also Hayes \& Matusov, 2005). Matusov asks: "Is it pedagogically (and morally) inappropriate to place a student in a situation, which forced the student to accept 'the right option', like leading-option questions do?" (2009, p. 35). Socrates and teachers of his ilk do not explain context and see their role as to provoke student learning without challenging one's own position. Such practices are ineffective because they leave students ill-equipped when faced with real world problems and are unethical on the grounds that they are predicated on rigid authoritarianism. Student and teachers can both be educated on important issues when engage because uncertainties open up anything for legitimate discussion and students learn that learning is not a temporary process.

\section{Dialogic Pedagogy \& Strong Evaluations in the Conduct of Everyday Life}

The foregoing work on the conduct of everyday life and strong evaluations resonates well with dialogic pedagogy. The latter fits well with the conduct of everyday life because the attempt to engage students' lives and mitigate teacher authority is about the manifestation of student experience. The ethos 
of collaborative learning and challenging social structures in dialogic pedagogy is echoed in the conduct of everyday life. Undoing social structures in the classroom is possible because they are constituted in interpersonal practices in the conduct of everyday life. Likewise, the conduct of everyday life involves complex social relationships where students and teachers must negotiate difficult tensions. The absence of a single social situation, per se, resonates well with the dialogic interplay that is so prominent in dialogic pedagogy. The emphasis on community of learners that test ideas in dialogic pedagogy consequently aligns with the complexities of a multicultural classroom like we see in the conduct of everyday life.

Just like the conduct of everyday life with strong evaluations paves the way for agency, dialogic pedagogy does the same. Far from abstracting learning away from the communities in which people are participants, dialogic pedagogy makes room for the kind of communal realities that predicate strong evaluations. The responsibility to others and emphasis on communities necessary for the conduct of everyday life are integral to dialogic pedagogy. Recall how the conduct of everyday life involves strong evaluations that lead to changing subjectivities of students and teachers. Dialogic pedagogy also looks to the same kind of change and so we see an articulation of principles in dialogic pedagogy rearticulated in the conduct of everyday life involving strong evaluations.

\section{Challenges for Dialogic pedagogy}

Strong evaluations raise the issue of quality in the classroom and so raise a generative point of tension between dialogic pedagogy and the forgoing: the responsibility to be strong evaluators. This issue is a difficult one because proponents of dialogic pedagogy may raise the challenge of "whose quality". After all, notions of quality are often associated with the metrics of standardized curricula. Taylor's work on strong evaluations, however, raises the issue of quality without collapsing into hegemonic oppression. Strong evaluations are about the difference between first and second order desires. This distinction leads to a kind of critical self-reflection that is about contested values and ways of life and not about standardized content. As such, when proponents of dialogic pedagogy raise the issue of ontological dialogue, Taylor offers an articulation of what such ontological engagement looks like. Taylor is very clear that strong evaluations are about what matter to people and this resonates with ontological problembased learning like we see in dialogic pedagogy. The kinds of tensions that we see in the conduct of everyday life involving strong evaluations fits well with the kind of dialogue we see in dialogic pedagogy, but they open up the potential of two challenges to dialogic pedagogy.

\section{Challenge 1: Disengagement}

I want to address a challenge that we need to bear in mind as we move forward in our work in dialogic pedagogy and this challenge is the threat of disengaged individualism. This threat ties into what I mentioned above in reference to how education that seeks student engagement can do so on the grounds of weak evaluations. When Taylor (1989) traces the development of the kind of self we see in modern individualism, he fleshes out in more detail how people are set up to fall into weak evaluations. My position is that education is not insulated from this propensity.

Individualistic self-responsibility is one feature of the contemporary conduct of everyday life that enables disengagement. Taylor writes that the

philosophy of disengagement and objectification has helped to create a picture of the human being, at its most extreme in certain forms of materialism, from which the last vestiges of subjectivity seem to have been expelled. It is a picture of the human being from a completely third-person perspective. (1989, pp. 175-176). 
This third-person perspective refers to the rational and objective control and view of oneself and life. It is about a Cartesian struggle or pull one's rational capacities away from the distractions of the body that include emotions and other such 'irrational' experience. One gains self-mastery through reason abstracted from life and therein one is able to shape oneself through deliberate rational. One is responsible to disengage from the attachments in everyday life and shape a self-hood grounded in pure logic. This rational control of the self is an idea that lies in our tacit consciousness of individual selfresponsibility. Descartes and Kant set the stage for this perspective and, in reference to moral ontologies,

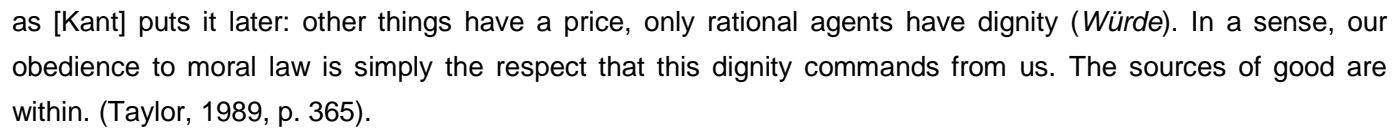

Sources of good are not treated as socio-linguistic or communally constituted because they are found in the responsibility of an individual to pursue logic.

Such individualistic self-responsibility that we see permeating late-modern societies amounts to an untenable disengagement. Taylor (1999) elaborates on the problem with individualistic selfresponsibility ten years after Sources of the Self and explains why it amounts to disengagement. He does so by challenging another Cartesian: Jean-Paul Sartre and the latter's discussion of radically free choice. Sartre's claim was that we need to strip ourselves of attachments to be radically free and make decisions about what is right to do. Taylor's critique is that we cannot understand our responsibility for our evaluations through the notion of radical choice. He presents Sartre's discussion of a young man during the second world war who wants to simultaneously leave home to fight for the French resistance and stay home to care for a sick mother. Sartre, in saying the young man needs to become detached to make a choice, is wrong according to Taylor. It is only a difficult situation precisely because the options are not created by rational choice. An agent of radical choice has to choose like the simple weigher because there is no conception of a 'pull' possessed by either option. The real force of the dilemma comes from the sense that there are different moral perspectives entailed in strong evaluations:

\footnotetext{
When we see what makes the theory of radical choice plausible, we see how strong evaluation is something inescapable in our conception of the agent and his experience; and this because it is bound up with our notion of the self $(1999$, p. 33).
}

To lose these qualities is to lose the very possibility of being an agent who evaluates. An agent of radical choice has no horizon of evaluation and it is for this reason that a perfect detachable consciousness that deals with issues that matter is an illusion - a dangerous illusion, because it denies life itself, and others as people to whom one is answerable.

Particularity is another feature of the contemporary conduct of everyday enables disengagement. Where one part of the conduct of contemporary everyday life involves self-responsibility and individuality emerging from Descartes' call for radical disengagement from ordinary experience, Taylor notes how Montaigne requires deeper engagement with one's own particularity. Previous eras and philosophies were concerned with finding universal human nature and looking within oneself to find such commonalities. There was a shift following the radical enlightenment from looking within oneself for universal human nature to looking within oneself to find one's own being. Self-knowledge particular to oneself becomes important after expressionism as Taylor writes: 


\begin{abstract}
What is new in the post-expressivist era is that the domain is within, that is, it is only open to a mode of exploration that involves a first-person stance. That is what it means to define the voice or impulse as 'inner'. ... The sense of depth in inner space is bound up with the sense that we can move into it and bring things to the fore. (1989, pp. 389-390).
\end{abstract}

The idea is that we "have" particular selves in the same way that we have a body part that is uniquely ours. Interiority and passion of self comes from radical interiority of this sort that puts us in a state of tension. On the one hand, we conduct contemporary individualist life with an ethos of Cartesian individuality and disengagement. The Cartesian disengagement entailed in self-responsibility/individuality means to disconnect from the experiential qualities of everyday life that are essential for strong evaluations. On the other hand, we deeply engage ourselves to explore our own passions and desires that we hide even from ourselves. Even though late modern subjectivities are paradoxical, particularity nevertheless means a more robust disengagement from others and the communities in which we live. This problematic perspective means that self dissolves in a void, without boundaries in its individualist isolation. Taylor is pointing out how people can miss important parts of their relationships with others and not arguing that people are missing a connection with some sort of higher community consciousness. Delving into one's own passions can run the risk of missing how others offer important boundaries and relational touch points that help shape our selves. Overall, he is warning that the wider contexts of and webs of relations that ground strong evaluations are displaced in favor of one's particular self-exploration.

Personal commitment is a third feature of the contemporary conduct of everyday life that enables disengagement. This feature refers to a radical shift that took place in terms of commitment to spiritual practices and alignment with some sort of moral or cosmic order. Whereas commitment to such universal orders was the vocation of elites such as priests or aesthetes, the enlightenment and renaissance lead to a call for all persons to make such commitments. In tandem with self-responsibility/individuality and particularity, this change means that personal commitment is not to a theory of cosmic logos. It is not just the elite who were committed to the faith but all people must commit deeply and the thing to which one become committed is oneself. What comes from this transition is the social leveling as 'higher' activities come under vigorous criticism. Social leveling in the value of everyday life can be seen in the interest in everyday life in the art and literature. Taylor writes that

\footnotetext{
This three-sided individualism is central to our modern identity. It has helped fix that sense of self which gives off the illusion of being anchored in our very being, perennial and independent of interpretation. ... the growth of forms of inwardness, correlative of the increasing centrality of reflexivity in spiritual life, and the consequent displacement of moral sources. But what may seem to common sense even more basic and unchallengeable is the location in general of the properties and nature of something 'in' that thing, and in particular, the location of thought 'in' the mind. ... Thought and feeling - the psychological - are now confined to minds. (1989, pp. 185186).
}

Hence, there is the emergence of the ethic of being true to oneself and personally committing to holding to such individualistic truth. The result is a disengaged individualism that focusses on oneself in denying higher callings, which reduces human motivation to pleasure and weak evaluations. Hence, it compounds disengagement by precluding strong evaluations.

Taylor's (1989) discussion of late-modern subjectivities illustrates how dialogic pedagogy especially in North America - is challenged by a propensity of students to fall back into disengagement. Individualistic self-responsibility, particularity, and personal commitment are likely to be present forces in 
the classroom. The radical restructuring and freedom we seek to promote in dialogic pedagogy makes it easy for students who are all-too-ready to fall back into disengagement, which therein undermines dialogue. It is clear that conventional education forces students into a kind of alienation from the classroom, either through weak evaluative style or obsession with external trappings of 'success' like grades. My concern is that a dialogic classroom does not necessarily provide an easy antidote. Students can potentially transition from a very monologic, authoritarian pedagogical regime, into an open, democratic regime, and require "detoxification" from the mangles of totalitarianism. This would be a period of time where they can do nothing by obligation. Disengagement could be a particular circumstance of transitioning from an authoritarian to a democratic educational governance regime.

There is a path between two extremes that, I think, we need to navigate dialogic pedagogy. Practitioners of dialogic pedagogy may attempt to undo alienation from standardization, but as Shor (1987) intimated, they dispositionally fall back into presupposed tacit ideologies of disengagement. The path of least resistance is a danger to dialogic pedagogy and dialogue in the classroom because such disengagement we see in some wider communities - a disengagement promoted by neoliberal machinations that need docile adherents. It is not just with school, but the conduct of everyday life is potentially marked by personal commitment to an individualist modus operandi that precludes dialogue. It could well be that many students are dispositionally oriented towards weak evaluations and dialogic pedagogy may be just another first-order option in which this happens. After all, we cannot compel engagement and have a dialogic climate in a classroom.

\section{Challenge 2: Pedagogical Eros}

While, on the one hand, I described above the challenge of disengagement, on the other hand, there is a converse issue: engagement that entails eros. Plato's Symposium involves a discussion of love and simultaneously reflects on education. It contains a speech by Alcibiades, who fancies himself to be Socrates' pupil and his speech illuminates a challenge to dialogic pedagogy:

\footnotetext{
The first time a person lets himself listen to one of Socrates' arguments, it sounds ridiculous. ... But if you could see them opened up, if you can get through to what's under the surface, what you will find is that his arguments are the only ones in the world that make sense. And that's not all: under the surface his arguments abound with divinity and effigies of goodness. They turn out to be extremely far reaching, or rather the cover absolutely everything which needs to be taken into consideration on the path to true goodness (Plato \& Waterfield, 2008, p. 69).
}

The hyperbole in Alcibiades' comment illustrates how there can be students who ontologically engage in pedagogy and have this kind of awakening where ideas come alive to them. They can come alive to the ideas of a pedagogue in a dangerous way where a teacher's voice eclipses all others like we see in this excerpt from the speech. This change can happen at all levels of pedagogy and it is a powerful experience because of the ontological quality of strong evaluations.

What often comes with such change is a complex kind of eroticism - one that goes beyond mere sex - and Alcibiades is deeply impacted by his love for Socrates. Part of this eroticism is seen in how viscerally Alcibiades describes his experience:

In fact, I've been bitten by something with far more excruciating bite than a snake, and it couldn't have attacked

a more vulnerable part of me. My heart or mind ... has been struck and bitten by philosophy, and when

Dialogic Pedagogy: An International Online Journal | http://dpj.pitt.edu

DOI: 10.5195/dpj.2016.182 | Vol. 4 (2016) 
philosophy seizes a young man of caliber, it clings more fiercely than any snake and makes him do all sorts of things. (Plato \& Waterfield, 2008, p. 64).

Themes of masochistic eroticism permeate Alcibiades' speech as he describes the influence that Socrates has had on him. The masochistic eroticism is not the only way that Socrates sees pedagogical eros taking shape. Of course, Plato's obsession with the ideal type of love lurks in the background of this speech and reinforces that pedagogical eros is not just about sex: it is about an ideal kind of love. It is possible to move away from the hegemony of the ideal forms while taking the cue that we are not just talking about eros in a shallow sense. It is a richer concept involving broad desire and affection. Steiner (2003) discusses the Symposium at length and points out how people love or hate Socrates as they come under the spell of the master. Eroticism is interwoven with the phenomenology of mastery and discipleship and Steiner argues that education involves the "totalities of the mind and body [being] enlisted" in education (p. 26). Class can generate an "atmosphere saturated with tensions of the heart" (p. 27). Thirst for dialogue creates the penetrative tenderness of mastery and discipleship. The Symposium describes love in relation to education and Socrates' discussion of love starts from a discussion of how to love something is to desire it insofar as it is something not in one's possession that one desires. Pedagogical eros therein includes desire of something else that one sees in another. In the case of Alcibiades, it is the learned quality of Socrates that he wants. There is a deep identification between the instructor and the pupil as the pupil wants something the instructor has. There is something attractive in Socrates' knowledge that Alcibiades desires and it is the far reaching quality of Socrates' understanding. To phrase this in terms of the conduct of everyday life and strong evaluations, it is the opening up of critical consciousness that we see becomes possible in ontological dialogues.

Steiner's (2003) position is that education is, on the one hand, a journey where students and pedagogues move together through life. A teacher gives an example through living as "[e]xemplary teaching is enactment and can be mute" as "Socrates and the saints teach by existing." (ibid. p. 4). Education is therein a journey where to educate means to lead forth together through strong evaluations in the conduct of everyday life. This journey amounts to a partnership between the master and the pupil is the axis of journey. Just as Dante is lead through hell with his teacher, Virgil, Steiner argues that educators walk with their students through the difficulties of hell - i.e. the existential angst of strong evaluations. Students progressively move away from the master as they go from hell to heaven, which means that the teacher takes students through the struggle of initial strong evaluations and they move on to managing such radical reflexivity on their own.

Eros is important to engagement, but not all teachers are the same in terms of their relationships with students as we see in hooks' $(1993,2003)$ discussion of eros and the potential for violence that we saw in the Symposium. She, like Steiner and Plato, sees eros as an essential part of the classroom because

\footnotetext{
[u]nderstanding that eros is a force that enhances our overall effort to be self-actualizing, that it can provide an epistemological grounding informing how we know what we know, enables both professors and students to use such energy in a classroom setting in ways that invigorate discussion and excite critical imagination. (1993, p. $60)$.
}

Self-actualizing pertains to the identification and development that comes with engagement in strong evaluations. The epistemological grounding that hooks writes about is that our ontological engagement entwines with how we know how to live in everyday life. We often feel our way through life and relations 
with others and education is not unique insofar as it is not neutral objective ground. Special bonds and affection have always existed in the pedagogical relationships. Moreover, instructors are instructed to bring love and passion to the classroom and there is substantial force directing faculty to go beyond the mere transmission of information in their pedagogy. She resonates with the forgoing by arguing that people enter the classroom as embodied and feeling agents who are holistic beings. Paradoxically, such discussion of the body is simultaneously a betrayal of the legacy of denial and repression of the body in favor of abstract logic. hooks sees such a betrayal as a good thing because it is absurd to deny eros in the classroom implied in holding to an artificial split between private/passionate personal lives and public/dispassionate public lives. Such a dichotomy becomes irrelevant when there is an honest acknowledgement of eros in the classroom. Her claim is that we must live with eros and move beyond it as just sexual if we are to deal with the potential for violence inherent in it.

It is here how, on the other hand, there is a dark side to pedagogical eros and the journey taken by students and teachers. The dark side is the inevitable realities of power relations and Steiner (2003) identifies how teaching is an exercise in power relations. Consider how he writes that, at times,

\footnotetext{
[t]o teach something is to lay hands on what is most vital in a human being ... A master invades, he breaks open, he can lay waste in order to cleanse and rebuild. Poor teaching, pedagogic routine, a style of instruction which is consciously or not, cynical in its merely utilitarian aims, are ruinous. They tear up hope by its roots. Bad teaching is, almost literally, murderous and, metaphorically, a sin. It diminishes the student, it reduces to gray inanity the subject being presented. (p. 18).
}

He also writes how a "charismatic master, an inspired 'prof' take in hand, in a radically 'totalitarian' psychosomatic grasp, the living spirit of their students or disciples." (p. 27). This experience certainly does not mark all students to such a degree. It is, however, indicative of the kind of destructive power that a teacher can have in light of the erotic energy entailed in teaching. Cynical dialogue that undermines metanarrative can tear students up and leave them in states of despair. Crushing relativism that a critical consciousness raises can lead to perpetual strangeness from life as usual. Cynical deconstruction can leverage eros to a destructive end where students give up. Hence, Steiner writes about how teaching involves love and the darkness of love, which is when the erotic and abstention that leads to strangeness and more alienation. There is a tremendous potentiality for violence entwined with pedagogical eros when there is student engagement.

hooks (2003) is clear that the dark side of pedagogical eros can be seen in abuse of power by faculty. While there can be positive erotic bonds between an instructor and students, it can be violent and exploitive. Hence there are college policies prohibiting relationships that have even an erotic veneer. She points out that there are faculty who should not be tolerated and these are the ones that need power imbalances to "get it up and keep it up" (ibid., p. 148). Since student development can be the context where erotic longings occur, passionate pedagogy spawns erotic energy that can be misused. Steiner (2003) notes that "Schoolmasters, trainers of mind and body, aware of what is at stake, of the interplay of trust and vulnerability, of the organic fusion between responsibility and response (what I will call answerability) are alarmingly few." (p. 18). What he and hooks are driving at is that unreflective exploitation is not the kind of pedagogical eros that realizes good pedagogy. Barring such exploitive actors but allowing for eros means that desire can be acknowledged among unequal partners that is nonabusive and a community of learners can test relationships like all other aspects of education. Instead undermining students as being impotent through representing them as having no choice, eros can be acknowledged and be part of exploring how people learn to be just in situations of power imbalance. That 
is, it is possible to hold people accountable instead of precluding recognition of accountability and responsibility when deny erotic feelings that emerge between teacher and students.

The kind of community of learners that dialogic pedagogy promotes sets up conditions for pedagogical eros to emerge. In one very basic way, dialogic pedagogy sets up the conditions for eros with the erosion of boundaries that were sustained through conventional education. When students and teachers are equalized and there is an erosion of conventional boundaries, it is easier for eros to emerge. The boundaries around relationships also likely erode and pave the way for more eroticism in education. The point is that there is no dispassionate engagement when one is ontologically engaged in dialogical pedagogy.

Furthermore, a community of learners sets up the condition for eros because students who engage in ontological eros are put in a place where traditional forms of telos are eroded. The ethos of ontological dialogue entails strong evaluations that are not immediately resolved, which is the case in terms of weak evaluations. Strong evaluations in the conduct of everyday life create a climate where traditional sources of authority become relativized and finding personal direction becomes existentially tougher. As teachers open up space for more strong evaluations in dialogical pedagogy, they open up new understandings and a richer conduct of everyday life. Such change means that the conduct of everyday life involves heightened engagement and critical self-reflection that we seek to see in a community of learners. It is a conduct of everyday educational life that opens up ontologically pervasive strong evaluations.

This experience can be tough to students and it leads to erotic desire and so Steiner (2003) writes about how teaching involves love and the darkness of love, which is when the erotic and abstention that can lead to alienation from the life before what dialogic pedagogy would consider ontological dialogue. Eros is entwined with a desire for what someone else has and, in this case, it is the experience of being a strong evaluator. A teacher seems to live a life that an engaged student desires and the issue of eros needs to be discussed in dialogic pedagogy. The teacher-student relationship needs to be discussed because the eros it entails can lead to a subversion of dialogue.

The importance of the student-teacher relationship and equality that is pursued in dialogic pedagogy means that we need to face the issue of pedagogical eros. There is the issue of the dark side of eros where abuses can happen. Dialogic pedagogy needs to address how such abuse is understood and defined in ways other than shallow harassment-prevention policies that we see in bureaucratic schooling. This direction means talking about the admission and negotiation of power in ways that are non-abusive, yet do not suppress or overly sexualize pedagogical eros. How do we understand the flourishing of healthy dialogue in light of pedagogical eros? Considering this question means that taking a strong stance on the incidental quality of the teacher may be more complicated than is currently presumed in dialogic pedagogy. The complexities of relationships need to be careful discussed because it is not so easy to dismiss the special role of the teacher and sustain ontological dialogue.

\section{Concluding... Not!}

In this editorial, I drew on my background and recent experience with DPJ to lay out the groundwork for two issues l'd like to see discussed in the area of dialogic pedagogy. Namely, disengagement and pedagogical eros are two issues that I argued for addressing. Scholarship on the conduct of everyday life opens up a new area for readers interested in dialogic pedagogy. Its emphasis on the first person stance and the issues of power in relation to resistance provide generative material for discussion. I added the notion of strong evaluations because I have been struggling for a while with how 
to talk about quality without hegemony. Strong evaluations are dynamic and they allow us to talk about quality in education without falling prey to monologism or neoliberal consumer anesthesia. These genres of scholarship both resonate and challenge dialogic pedagogy, which is what we ought to do in DPJ.

\section{References}

Arya, D, \& Parker, J. (2015). Dialogic action in climate change discussions: An international study of high school students in China, New Zealand, Norway and the United States. Dialogic Pedagogy, 3, 131-157.

Bain, K. (2004). What the best college teachers do. Cambridge: Harvard University Press.

Cresswell, J. (2011). Being Faithful to Ourselves: Bakhtin and a Potential Postmodern Psychology of Self. Culture \& Psychology, 17, 462-479.

Dreier, O. (2016). Conduct of everyday life: Implications for critical psychology. In E. Schraube \& C. Højholt (Eds.) Psychology and the conduct of everyday life (pp. 15-33). New York: Routledge.

Elkadar, N (2015). Dialogic Multicultural Education Theory and Praxis:Dialogue and the Problems of Multicultural Education in a Pluralistic Society. Dialogic Pedagogy, 3, 1-18.

Freire, P. (2000). Pedagogy of the Oppressed. New York: Continuum.

Hayes, R. \& Matusov, E. (2005). Designing for dialogue in place of teacher talk and student silence. Culture \& Psychology, 11(3), 339-357.

Holzkamp , K. ( 2013 ). Psychology: Social self-understanding on the reasons for action in the conduct of everyday life . In E. Schraube \& U. Osterkamp (Eds.), Psychology from the standpoint of the subject: Selected writings of Klaus Holzkamp (pp. 233 - 341 ) (A. Boreham \& U.Osterkamp , Trans.). Basingstoke : Palgrave Macmillan .

hooks, b. (1993). Eros, eroticism and the pedagogical process. Cultural Studies, 7(1), 58-63.

hooks, b. (2003). Good sex: Passionate pedagogy. In Teaching community: A pedagogy of hope (pp. 139-156). New York: Taylor \& Francis.

Højholt, C. \& Schraube, E. (2016). Introduction: Toward psychology of everyday living. In E. Schraube C. Højholt (Eds.) Psychology and the conduct of everyday life (pp. 1-14). New York: Routledge.

Kamberelis, G. Mcginley, W., \& Welker, A. (2105). Literature Discussions as Mangles of Practice: Sociological Theories of Emergence and/in Dialogic Learning Events. Dialogic Pedagogy, 3, 98130.

Lemberger, D. (2105). Dialogical Grammar: Varieties of Dialogue in Wittgenstein's Methodology. Dialogic Pedagogy, 3, 158-173.

Matusov, E. (2004). Guest editor's introduction: Bakhtin's dialogic pedagogy. Journal of Russian and East European Psychology, 42(6), 3-11.

Matusov, E. (2009). Journey into dialogic pedagogy. New York: Nova.

Matusov, E. (2015a). Legitimacy of non-negotiable imposition in diverse approaches to education. Dialogic Pedagogy, 3, 174-211.

Matusov, E. (2015b). Chronotopes in education: Conventional and dialogic. Dialogic Pedagogy, 3, 65-97. 
Matusov, E. \& Miyazaki, K. (2014). Dialogue on Dialogic Pedagogy. Dialogic Pedagogy, 2, 1-47.

Nissen, M. (2015). Meeting youth in movement and on neutral ground. Dialogic Pedagogy, 3, 19-42.

Plato \& Waterfield, R. (2008). Symposium (Trasnlated by R.Waterfield). Oxford: oxford University Press.

Postman, N. (1971). Teaching as subversive activity. New York: Delta.

Schraube, E. \& Marvakis, A. (2016). Frozen fluidity: Digital technologies and the transformation of students' learning and the conduct of everyday life. . In E. Schraube C. Højholt (Eds.) Psychology and the conduct of everyday life (pp. 205-225). New York: Routledge.

Shor, I. (1987). Critical teaching and everyday life. Chicago: University of Chicago.

Shor, I., \& Freire, P. (1987). What is the 'dialogical method' of teaching. Journal of Education, 3, 11-31.

Taylor, C. (1989). Sources of the self: The making of the modern identity. Cambridge: Harvard University Press.

Taylor, C. (1991). The malaise of modernity. Toronto: House of Anansi Press.

Taylor, C. (1999). Human agency and Language: Philosophical papers volume 1. Cambridge: Cambridge University Press.

\section{Acknowledgements}

I have often struggled with Bakhtin's claim in the Speech Genres essay that a written piece of work is a single utterance in a chain. This article is populated with so many voices that I find this claim hard to accept. I am indebted to the other editors of Dialogic Pedagogy Journal for reviews of an earlier draft, which has led to the inclusion of their voices. Thanks should be extended to them for support and assistance with developing a clearer utterance.

\section{(c)) EY}

New articles in this journal are licensed under a Creative Commons Attribution 4.0 United States License.

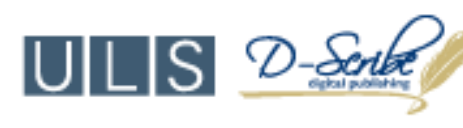

This journal is published by the University Library System, University of Pittsburgh as part of its D-Scribe Digital Publishing Program and is cosponsored by the University of Pittsburgh Press. 